\title{
Oxidative Ring Expansion of Cyclobutanols: Access to Functionalized 1,2-Dioxanes.
}

\author{
María Martín López, Nicolas Jamey, Alexis Pinet, Bruno Figadère, Laurent Ferrié* \\ BioCIS, Université Paris-Sud, CNRS, Université Paris-Saclay, Châtenay-Malabry, 92290 (France).
}

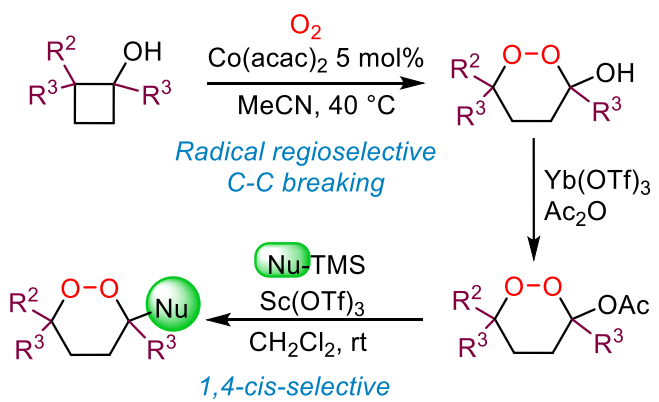

\begin{abstract}
Cyclobutanols undergo an oxidative ring expansion into 1,2-dioxanols by using $\mathrm{Co}(\text { acac })_{2}$ and triplet oxygen $\left({ }^{3} \mathrm{O}_{2}\right)$ as radical promoters. The formation of an alkoxy radical drives to the regioselective break of the strained ring with stabilization of a new radical on the most substituted side. The radical traps then oxygen to form 1,2-dioxanols. The reaction is particularly effective on secondary cyclobutanols but can work also on tertiary alcohols. Further acetylation generates peroxycarbenium species under catalytic Lewis acid conditions, which react with neutral nucleophiles. Many original 1,2-dioxanes, which would be difficult to prepare by another method, were then obtained with a preferred 3,6-cis-configuration. This method provides an interesting access to the total synthesis of many natural endoperoxides.
\end{abstract}

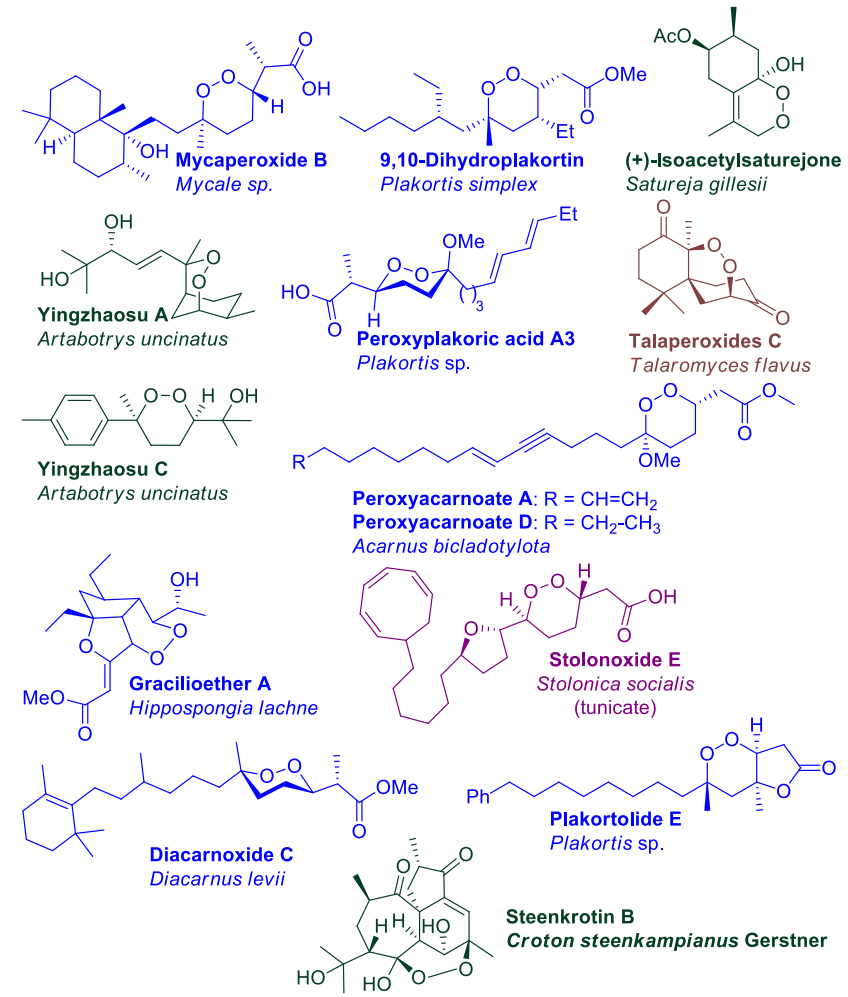

Figure 1. 1,2-Dioxane natural products involved in total synthesis studies (In blue, isolated from sponges; in purple, from other marine species, in green, from plants; in brown from fungi).
1,2-Dioxanes are a particular example of endoperoxides, which can be found in many natural products. They are mainly isolated from various sponges but also from other marine species, plants, and fungi. ${ }^{1}$ Most of natural dioxanes display antiparasitic, antifungal, or cytotoxic activities. Although hundreds of these natural substances were reported with more or less variety in their structures, relatively few works were driven towards their total synthesis. (Figure 1).

Many of these synthetic studies were targeting natural products isolated from marine species, and more specifically marine sponges. Indeed, sponges are known to be a tremendous pool for endoperoxides, and 1,2-dioxanes represent a large part of them. Nevertheless, other natural products with a 1,2-dioxane scaffold, produced by other marine species, fungi or plants, were studied for their total synthesis. Indeed, synthetic works toward mycaperoxyde $\mathrm{B},{ }^{2} 9,10$-dihydro-plakortin, ${ }^{3}$ peroxyplakoric acid $\mathrm{A} 3,{ }^{4}$ peroxyacarnoate $\mathrm{A} \& \mathrm{D},{ }^{5}$ graciloether $\mathrm{A},{ }^{6}$ diacarnoxide $\mathrm{C},{ }^{7}$ plakortolide $\mathrm{E},{ }^{8,9}$ stolenoxides, ${ }^{10}$ talaperoxides and other derivatives of the chamigrane family, ${ }^{11}$ isoacetylsaturejone, ${ }^{12}$ yingzahosu $\mathrm{A}^{13,14} \& \mathrm{C},{ }^{15,16}$ and steenkrotin $\mathrm{B}^{17}$ were accomplished using different strategies to build the key 1,2-dioxane ring. ${ }^{18}$

These last years, our group was involved in a scientific program towards the total synthesis of mycangimycin, a polyunsaturated fatty acid containing an uncommon disubstituted 1,2dioxolane ring. ${ }^{19}$ Our strategy was to build the endoperoxide through an oxidative ring expansion of a cyclopropanol to a 1,2dioxolan-3-ol. ${ }^{20,21} \mathrm{We}$ discovered that the corresponding acetate 
can react with various silylated nucleophiles through either Sakurai or Mukaiyama reactions, catalyzed by strong Lewis acids such as $\mathrm{TiCl}_{4}$ or $\mathrm{SnCl}_{4}$ in quasi-stoichiometric amounts. ${ }^{22}$ The process was further improved by the use of milder catalysts, such as $\mathrm{Sc}(\mathrm{OTf})_{3}$ or $\mathrm{InCl}_{3} / \mathrm{TMSCl}$ in catalytic amount, which allows to run the reactions at room temperature with an expanded reagent scope (Scheme 1). ${ }^{23}$

Scheme 1. Oxidative ring expansion of strained cycloalkyl alcohols and further functionalization of the endoperoxyacetals.

$$
\begin{aligned}
& \text { Previous work: } \\
& \mathrm{O}_{2} \\
& 1 \mathrm{~mol} \%
\end{aligned}
$$

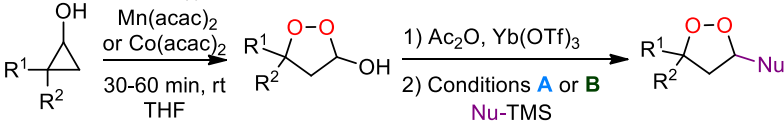

$$
\begin{aligned}
& \text { Conditions A: } \mathrm{SnCl}_{4} \text { or } \mathrm{TiCl}_{4},-40{ }^{\circ} \mathrm{C}, \mathrm{CH}_{2} \mathrm{Cl}_{2} \\
& \text { Conditions B: Sc(OTf) })_{3} \text { or } \mathrm{InCl}_{3} / \mathrm{TMSCl}, 5 \mathrm{~mol} \%, \mathrm{rt}, \mathrm{CH}_{2} \mathrm{Cl}_{2}
\end{aligned}
$$

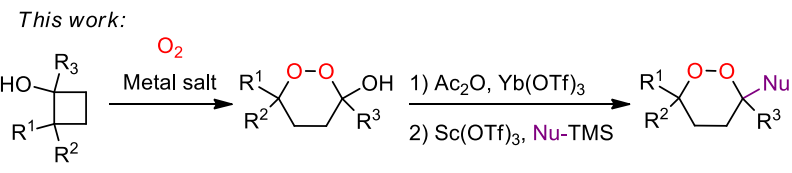

On the basis of this work, we were wondering if we could apply this strategy to the synthesis of functionalized 1,2-dioxanes. Indeed, Dussault earlier reported the nucleophilic substitution on 6-membered endoperoxyketal rings on 1,2-dioxene derivatives in some pioneering studies. ${ }^{24}$ In contrast, oxidative ring expansion of cyclobutanols under radical conditions was relatively unknown, and the difference of kinetics between cyclopropoxy and cyclobutoxy radicals, by analogy with the cyclopropylmethyl radicals ${ }^{25}$ and cyclobutylmethyl radicals, ${ }^{26}$ might not allow the expected transformation in our favor. Nevertheless, a few examples of ring opening of cyclobutyloxy radicals were reported in the literature, driving to the formation of 1,4-diketones under oxidative conditions, ${ }^{27}$ or to 4 -substituted ketone derivatives when the radical is trapped with some good radical acceptors. ${ }^{28}$ It is also important to note that during the total synthesis of graciloether A, the last key step included a radical transformation of a particularly strained cyclobutane ring into a 1,2 dioxolane (Scheme 1$){ }^{6}$

To study the oxidative ring expansion of cyclobutanols into 1,2-dioxolan-3-ols, the desired starting materials were first prepared. For this purpose, we found that the most general route was based on a Wittig olefination of ketones or aldehydes 1a-f with a cyclopropyl ylide. Further epoxidation with $m$-CPBA provided unstable spiro-epoxycyclopropanes 3a-f, which were converted into cyclobutanones $4 \mathbf{a}-\mathbf{f}$ through a pinacol rearrangement promoted by acid catalysis. ${ }^{29}$ On one hand, further reduction with $\mathrm{NaBH}_{4}$ gave cyclobutanols 5a-f as a mixture of diastereoisomers. Tertiary alcohols 6a-e were also synthesized, on the other hand, by addition of an organolithium or organomagnesium reagent onto cyclobutanones 4a-e (Scheme 2).

Scheme 2. Preparation of 2-substituted cyclobutanols 5a-f and 6a-e.

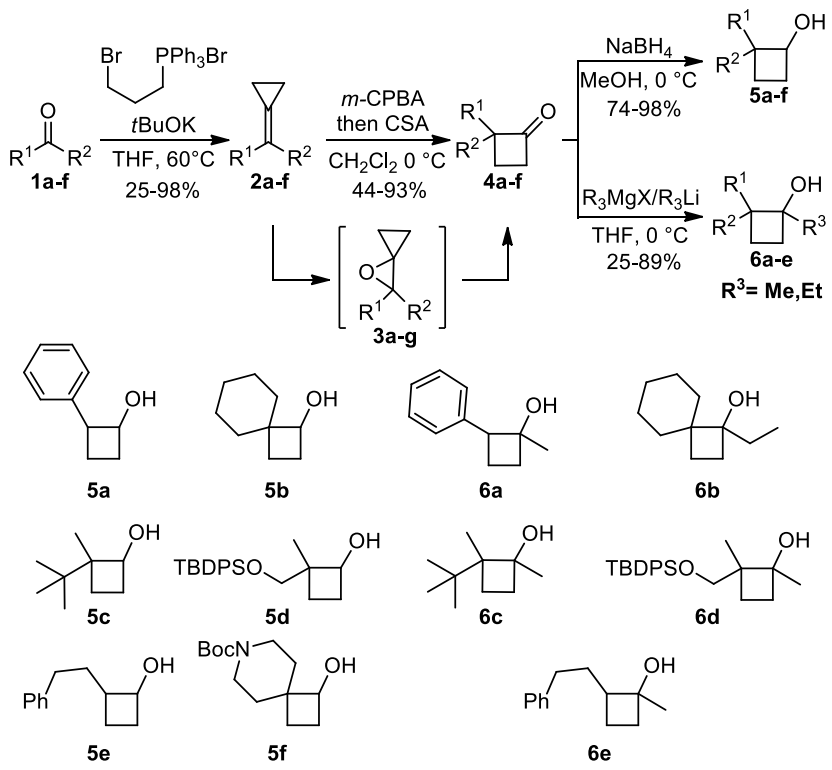

A first investigation of the oxidative ring expansion of cyclobutanols was conducted on cyclobutanol 5a. This substrate was particularly interesting to start the study with, as a driving force of the $\mathrm{C}-\mathrm{C}$ bond cleavage would be the stabilization of the new radical $^{29}$ into the intermediate opened product, and a benzene substituent could play perfectly this role.

\begin{tabular}{|c|c|c|c|c|c|}
\hline Entry & $\begin{array}{c}\text { Metal } \\
\text { salt }\end{array}$ & $(\mathrm{mol} \%)$ & Conditions & Solvant & $\begin{array}{c}\text { Yield }^{a} \\
(\%)\end{array}$ \\
\hline 1 & $\operatorname{Mn}(\mathrm{acac})_{2}$ & 1 & $\mathrm{rt}, 48 \mathrm{~h}$ & $\mathrm{THF}$ & No reaction \\
\hline 2 & $\operatorname{Mn}(\mathrm{acac})_{2}$ & 5 & $\mathrm{rt}, 48 \mathrm{~h}$ & THF & No reaction \\
\hline 3 & $\mathrm{Co}(\mathrm{acac})_{2}$ & 1 & $\mathrm{rt}, 24 \mathrm{~h}$ & THF & $23^{\mathrm{b}}$ \\
\hline 4 & $\mathrm{Co}(\mathrm{acac})_{2}$ & 5 & $\mathrm{rt}, 48 \mathrm{~h}$ & THF & $84^{\mathrm{b}}$ \\
\hline 5 & $\mathrm{Co}(\mathrm{acac})_{2}$ & 5 & $\mathrm{rt}, 48 \mathrm{~h}$ & $\mathrm{MeCN}$ & 61 \\
\hline 6 & $\mathrm{Co}(\mathrm{acac})_{2}$ & 5 & $40{ }^{\circ} \mathrm{C}, 8 \mathrm{~h}$ & $\mathrm{MeCN}$ & 76 \\
\hline 7 & $\mathrm{Co}(\mathrm{acac})_{2}$ & 100 & $\mathrm{rt}$ & $\mathrm{MeCN}$ & 56 \\
\hline 8 & $\mathrm{Co}(\mathrm{acac})_{3}$ & 5 & $\mathrm{rt}, 48 \mathrm{~h}$ & $\mathrm{MeCN}$ & traces \\
\hline
\end{tabular}

Table 1. Screening of conditions for oxidative ring expansion of cyclobutanol 5a into 1,2-dioxane 7a.

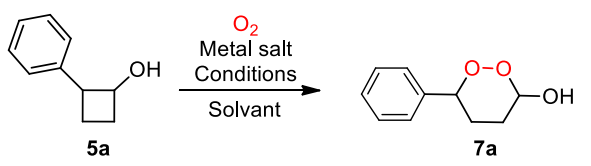

${ }^{a}$ Isolated yield as a 60:40 mixture of diastereomers. ${ }^{b}$ Yield was overestimated due to THF peroxides byproducts contamination.

By using reported conditions for the oxidative ring expansion of cyclopropanols, ${ }^{24-27}$ it was observed that cyclobutanol 5a did not react in presence of $\mathrm{Mn}(\mathrm{acac})_{2}$ (Table 1, entries 1 and 2). Gratifyingly, $\mathrm{Co}(\mathrm{acac})_{2}$ proved to promote strained cycle cleavage and be able to deliver a small amount of desired product over $48 \mathrm{~h}$ (Table 1, entry 3). Almost full conversion was attained with more cobalt salt (Table 1, entry 4), but yield was overestimated due to a large production of THF peroxide byproducts, which contaminated the desired product. These sideproducts were not observed, in contrast, on the ring expansion of cyclopropanols because of the fast scission process. To overcome this problem we switched THF for MeCN, which seemed inert to oxidation and allowed the transformation to occur, providing dioxane $7 \mathrm{a}$ in $61 \%$ yield after $48 \mathrm{~h}$ (Table 1, entry 5). 
Increasing the temperature to $40{ }^{\circ} \mathrm{C}$ could decrease significantly the reaction time to $8 \mathrm{~h}$ improving the overall process (Table 1 , entry 6). Using stoichiometric amount of cobalt(II) salt did not improve significantly the kinetic of the reaction, but lowered the yield due to the appearance of some degradations (Table 1, entry 7). Co(II) salt was essential to this reaction since starting directly from a source of $\mathrm{Co}(\mathrm{III})$ proved to be unproductive (Table 1, entry 8).

Oxidative ring expansion was then applied to other cyclobutanols 5b-f and 6a-e. Secondary alcohols 5b-f are, in general, best substrates for such a transformation. Indeed, the reaction works well, with 2,2-disubstituted cyclobutanols $\mathbf{5 b - d}$ and $\mathbf{5 f}$, affording isolated yields above $60 \%$. Mono-substituted cyclobutanol 7e were also able to undergo an oxidative ring extension but required a longer reaction time (up to $48 \mathrm{~h}$ ). We also observed no reaction at room temperature with this last substrates; meaning heating is a mandatory in that case. Tertiary alcohols 6a-e were also examined, and first trials were disappointing. Mono-substituted cyclobutanols $6 \mathbf{a}$ and $6 \mathbf{6}$ gave unsatisfactory results: no conversion into dioxane $\mathbf{8 e}$ was observed from $6 \mathbf{e}$. Isolation of diketone $\mathbf{9 a}$ and hydroxyketone $\mathbf{1 0 a}$ in $36 \%$ and $24 \%$ yield, respectively, from cyclobutanol $\mathbf{6 a}$ was experienced in place of dioxanol 8a. Isolation of these two unexpected products means the reaction was probably working but compound 8a might undergo a Kornblum-DeLamare rearrangement to form 9a in one hand, because the benzylic position facilitates an elimination process. In the other hand, hydroxyketone 10a might have been produced from 1,2-dioxane 8a by homolytic cleavage of the peroxide bond, but the exact pathway is for the while unclear. In contrast, it was found that 2,2-disubstituted cyclobutanols 5b-d and 5f were better substrates for an oxidative ring expansion. However the kinetic of this process was slower compared to secondary alcohols derivatives $\mathbf{6 b}-\mathbf{d}$, affording the desired products in lower yields with sometimes recovery of unreacted starting materials. This observation was unexpected and might be attributed to steric hindrance for the formation of the cyclobutoxy radical rather than a decrease of the kinetic of the cyclobutyloxy radical scission. (Scheme 3).

Scheme 3. Diverse attempts towards the synthesis of 1,2-dioxan-6-ols 7b-g and 8a-e.

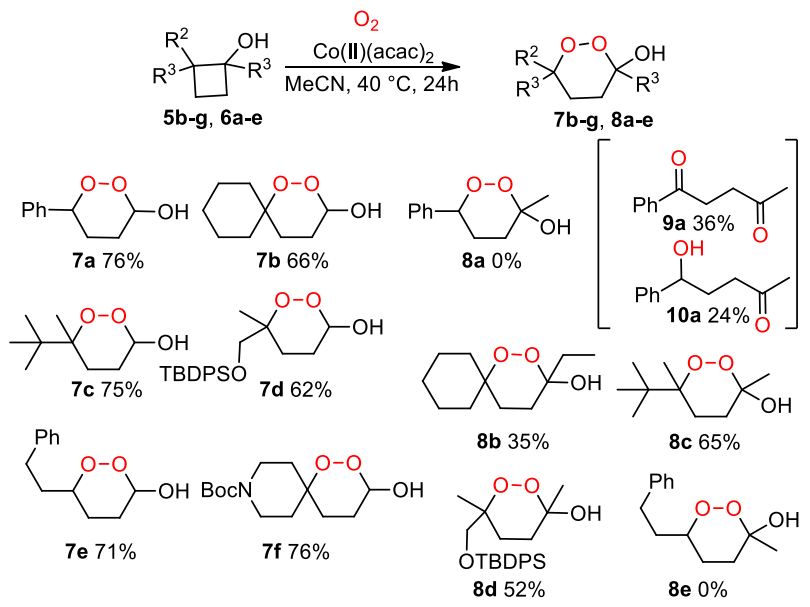

Although similar oxidation was reported in the literature, the exact mechanism has never been determined on how are formed peroxy radical species. ${ }^{27}$ It seems plausible that $\mathrm{Co}(\mathrm{II})(\mathrm{acac})_{2}$ is reacting with oxygen to form a superoxocobalt(III) radical. ${ }^{30} \mathrm{In}$ deed the reaction mixture, in presence of oxygen, turns rapidly from light brown color to intense green, which is a characteristic of Co(III) ions. These species seem then able to abstract an hydrogen from an hydroxy group to produce a new alkoxyradical, which can initiate the strained ring scission with stabilization of the radical at position 4. Regioselectivity in the carboncarbon bond cleavage is dependant of the ability of the new site to stabilize the new radical species. Therefore, this driving force explains some differences of reactivity between mono- and disubstituted cyclobutanols. A molecule of ${ }^{3} \mathrm{O}_{2}$ is then trapped by the radical, making a new peroxyradical, which can evolve between the opened form and the closed one. One or the other form might abstract a hydrogen from a new cyclobutanol to propagate the reaction. In this case superoxocobalt(III) radical seems to work as an initiator of the reaction rather than a catalyst (Scheme 4).

Scheme 4. Possible mechanism of the cyclobutanol oxidative ring-expansion.

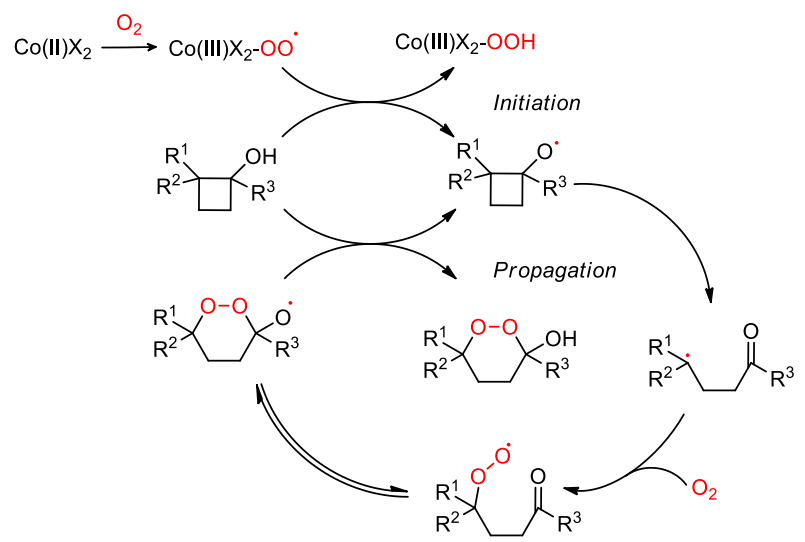

The so obtained 1,2-dioxanols 7a-g were then acylated using $\mathrm{Yb}(\mathrm{OTf})_{3}$ as a Lewis acid catalyst to produce different acetate derivatives 11a-g. ${ }^{26,27}$ Further functionalization of these compounds was initiated with different silylated nucleophiles. The catalytic version of the nucleophilic substitution using $\mathrm{Sc}(\mathrm{OTf})_{3}{ }^{27}$ was chosen for this screening for a better convenience. The reaction of acetate 11e with allylTMS drove to compound 12 as a sole cis-product in $65 \%$ yield. In contrast, reaction of acetate 11e with TMS cyanide was less selective and gave product 13 with only a cis:trans 65:35 ratio, while Mukayama aldol reaction with a ketene TMS-thioethylacetal furnished 1,2-dioxane $\mathbf{1 4}$ with a quite good diastereoselectivity. The synthesis of allyl 1,2-dioxane $\mathbf{1 5}$ from 11a was achieved in poor yield due to an elimination process which might take place more easily at the benzylic position, and produced many degradation products. ${ }^{26}$ Sakurai reaction on acetate $\mathbf{1 1 b}$ produced compounds 16 and 17 with pretty good yields. Mukaiyama reaction on acetate $\mathbf{1 1 b}$ with silyl enol ether of acetophenone gave dioxane $\mathbf{1 8}$ in good yield, and a vinylogous process was also possible to produce 19 from TMS-siloxyfuran as a 2:1 mixture of diastereomers. ${ }^{31}$ Reduction of acetal 11d with triethylsilane furnished compound $\mathbf{2 0}$ in moderate yield. With unsymmetrical dialkylated dioxanes 11c and 11d, the diasteroselectivity is not as good as with mono-substituted compounds, but generally a major isomer is observed such as in the synthesis of 1,2-dioxanes 21-24. Carbamate $7 f$ proved to be unreactive under our used Lewis acid catalysis, due to Lewis base properties of the nitrogen function (Scheme 5).

The diastereoselectivity in this nucleophilic substitution leads to the 1,4-cis diastereomer as a major product, in an analogous manner to 4-substituted tetrahydropyranyl acetals. ${ }^{32,33}$ If we consider dioxanyl acetate 11e for example, reaction with a 
Lewis acid drives to the formation of peroxycarbenium species, which adopt a half-chair like conformation. ${ }^{34}$ This species can evolve between conformations 27-eq and 27-ax, depending if the substituent is placed in axial or equatorial position. Because alkyl substituents prefer to adopt an equatorial position, the major reactive conformer must be 27-eq. A nucleophilic substitution takes then place preferentially to the axial position of the peroxycarbenium species, which lead 27-eq to compound 28cis. In contrast, diastereoselectivity is poorer from 6,6-disubstituted-1,2-dioxannyl acetates, although 11c gave decent selectivity's due to the bulky $t$-butyl group $(75: 25$ and $85: 15$ selectivity for $\mathbf{2 3}$ and $\mathbf{2 4}$, respectively). (Scheme 6).

Scheme 5. Functionalization of 1,2-dioxanyl acetates 11a-g.

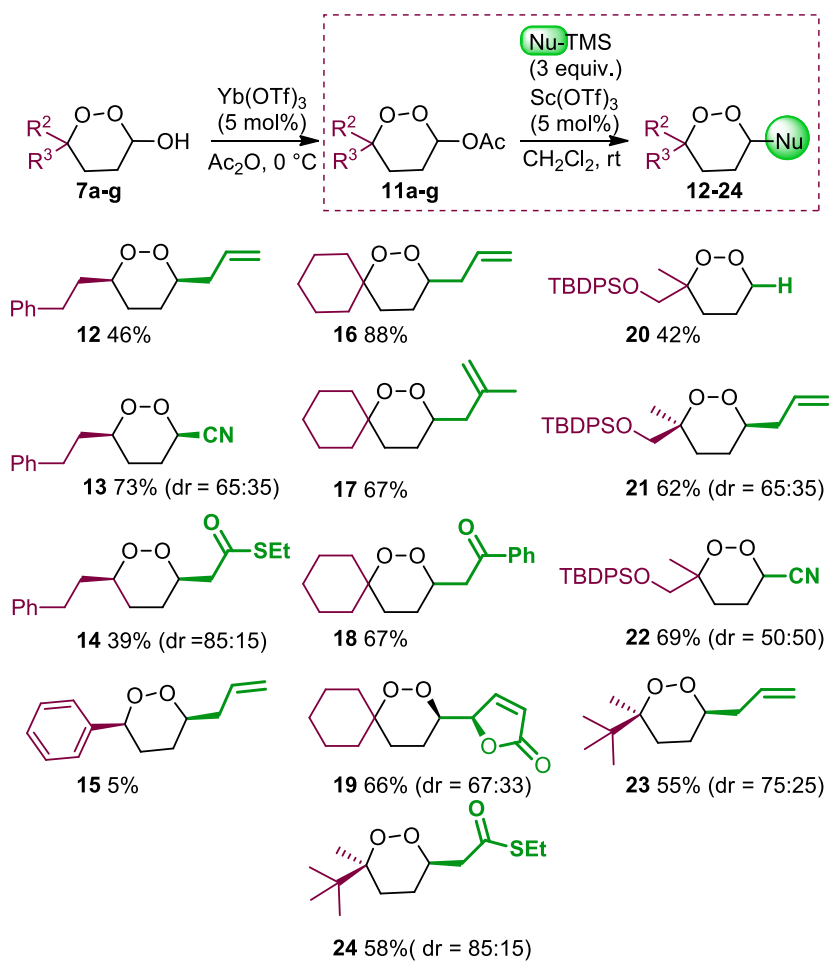

Scheme 6. Rationalization of the observed selectivity towards the 1,4 cis-diasteroisomer in the nucleophilic substitution of 1,2-dioxanyl acetates.

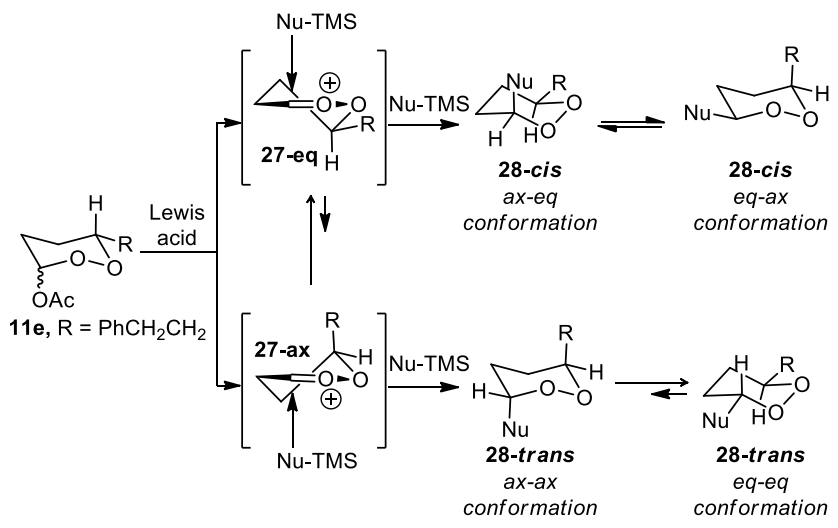

In conclusion, we developed a new access to 1,2-dioxanes, by using an original approach involving an oxidative ring expansion of cyclobutanols under radical conditions. The oxidation is regioselective and its kinetic seems dependant of the ability of the substituents to stabilize an intermediate alkyl radical. The process seems to work particularly well with secondary alcohols even if specific examples of tertiary alcohols can also moderately work sometimes. Further functionalization was then achieved. For instance, the corresponding acetates 11a-g, by generating reactive peroxycarbenium species, react with neutral nucleophiles to afford expected 1,2-dioxanes, preferentially as the 1,4-cis diastereoisomers. This new method is able to provide quickly functionalized 1,2-dioxanes, which would be difficult to obtain by another method. Indeed, it would be very valuable for the synthesis of new endoperoxides, but in particular for the total synthesis of natural marine products containing a 1,2-dioxane moiety such as mycaperoxides, stolonoxides, dihydroxyplakortides, diacarnoxide $\mathrm{C}$ and many others, whose structures seem to correspond to potential targets for its use.

\section{ASSOCIATED CONTENT}

\section{AUTHOR INFORMATION}

\section{Corresponding Author}

*E-mail: laurent.ferrie@u-psud.fr

ORCID

Laurent Ferrié: 0000-0002-1171-205X

Bruno Figadère: 0000-0003-4226-8489

\section{Notes}

The authors declare no competing financial interest.

\section{ACKNOWLEDGMENT}

N.J. and A.P. thank the Ministère de l'Enseignement Superieur, de la Recherche et de l'Innovation (MESRI) for a PhD fellowship. M. M. M. thank th European Union for . We thank Nina Cooper (Université Paris-Saclay) for exploratoring studies, Karine Leblanc for HRMS analysis (BioCIS, Châtenay-Malabry) and Jean-Christophe Jullian (BioCIS, Châtenay-Malabry) for NMR services.

\section{REFERENCES}

(1) (a) Liu, D.-Z.; Liu, J.-K. Peroxy Natural Products. Nat. Prod. Bioprospect. 2013, 3 (5), 161-206. https://doi.org/10.1007/s13659013-0042-7.(b) Casteel, D. A. Peroxy Natural Products. Nat. Prod. Rep. 1999, 16 (1), 55-73. https://doi.org/10.1039/A705725C.

(2) Silva, E. M. P.; Pye, R. J.; Brown, G. D.; Harwood, L. M. Towards the Total Synthesis of Mycaperoxide B: Probing Biosynthetic Rationale. Eur. J. Org. Chem. 2012, 2012 (6), 1209-1216. https://doi.org/10.1002/ejoc.201101477.

(3) Gemma, S.; Gabellieri, E.; Sanna Coccone, S.; Martí, F.; Taglialatela-Scafati, O.; Novellino, E.; Campiani, G.; Butini, S. Synthesis of Dihydroplakortin, 6-Epi-Dihydroplakortin, and Their C10-Desethyl Analogues. J. Org. Chem. 2010, 75 (7), 2333-2340. https://doi.org/10.1021/jo1001559.

(4) Xu, C.; Schwartz, C.; Raible, J.; Dussault, P. H. Asymmetric Synthesis of 1,2-Dioxanes: Approaches to the Peroxyplakoric Acids. $\begin{array}{llll}\text { Tetrahedron } & \mathbf{2 0 0 9}, & 65 & \text { (47), }\end{array}$ https://doi.org/10.1016/j.tet.2009.09.068.

(5) Xu, C.; Raible, J. M.; Dussault, P. H. Total Synthesis of Peroxyacarnoates A and D: Metal-Mediated Couplings as a Convergent Approach to Polyunsaturated Peroxides. Org. Lett. 2005, 7 (12), 25092511. https://doi.org/10.1021/ol050291m.

(6) Li, Q.; Zhao, K.; Peuronen, A.; Rissanen, K.; Enders, D.; Tang, Y. Enantioselective Total Syntheses of (+)-Hippolachnin A, (+)-Gracilioether A, (-)-Gracilioether E, and (-)-Gracilioether F. J. Am. Chem. Soc. 2018, 140 (5), 1937-1944. https://doi.org/10.1021/jacs.7b12903. 
(7) Schneider, M.-A.; Seifert, K. Towards the Total Synthesis of the Norsesterterpene Diacarnoxide C. Eur. J. Org. Chem. 2017, 2017 (45), 6739-6746. https://doi.org/10.1002/ejoc.201700922.

(8) Jung, M.; Ham, J.; Song, J. First Total Synthesis of Natural 6Epiplakortolide E. Org. Lett. 2002, 4 (16), 2763-2765. https://doi.org/10.1021/ol026285x.

(9) Barnych, B.; Vatèle, J.-M. Total Synthesis of Seco-Plakortolide $\mathrm{E}$ and (-)-Ent-Plakortolide I: Absolute Configurational Revision of Natural Plakortolide I. Org. Lett. 2012, 14 (2), 564-567. https://doi.org/10.1021/ol203185f.

(10) Hu, L.; Lu, X.; Deng, L. Catalytic Enantioselective Peroxidation of $\alpha, \beta$-Unsaturated Aldehydes for the Asymmetric Synthesis of Biologically Important Chiral Endoperoxides. J. Am. Chem. Soc. 2015 137 (26), 8400-8403. https://doi.org/10.1021/jacs.5b05345.

(11) Chen, H.-J.; Wu, Y. Expeditious Entry to the Chamigrane Endoperoxide Family of Natural Products. Org. Lett. 2015, 17 (3), 592595. https://doi.org/10.1021/ol503603t

(12) Snider, B. B.; O’Neil, S. V. Synthesis of (-)-Acetylsaturejol and (+)-Isoacetylsaturejol. Syn. Comm. 1995, 25 (7), 1085-1091. https://doi.org/10.1080/00397919508012671.

(13) (a) Xu, X.-X.; Zhu, J.; Huang, D.-Z.; Zhou, W.-S. Total Synthesis of (+)-Yingzhaosu A. Tetrahedron Lett. 1991, 32 (41), 57855788. https://doi.org/10.1016/S0040-4039(00)93555-X. (b) Zhou, W.-S.; Xu, X.-X. Total Synthesis of the Antimalarial Sesquiterpene Peroxide Qinghaosu and Yingzhaosu A. Acc. Chem. Res. 1994, 27 (7), 211-216. https://doi.org/10.1021/ar00043a005.

(14) Szpilman, A. M.; Korshin, E. E.; Rozenberg, H.; Bachi, M. D. Total Syntheses of Yingzhaosu A and of Its C(14)-Epimer Including the First Evaluation of Their Antimalarial and Cytotoxic Activities. $J$. Org. Chem. 2005, 70 (9), 3618-3632. https://doi.org/10.1021/jo050074z.

(15) (a) Xu, X.-X.; Dong, H.-Q. Enantioselective Total Syntheses and Stereochemical Studies of All Four Stereoisomers of Yingzhaosu C. J. Org. Chem. 1995, 60 (10), 3039-3044. https://doi.org/10.1021/jo00115a019. (b) Xu, X.-X.; Dong, H.-Q. Enantioselective Total Synthesis of All Four Stereoisomers of Yingzhaosu C. Tetrahedron Lett. 1994, 35 (50), 9429-9432. https://doi.org/10.1016/S0040-4039(00)78561-3.

(16) (a) Boukouvalas, J.; Pouliot, R.; Fréchette, Y. Concise Synthesis of Yingzhaosu $\mathrm{C}$ and Epi-Yingzhaosu $\mathrm{C}$ by Peroxyl Radical Cyclization. Assignment of Relative Configuration. Tetrahedron Lett. 1995, 36 (24), 4167-4170. https://doi.org/10.1016/00404039(95)00714-N

(17) Xuan, J.; Zhu, A.; Ma, B.; Ding, H. Diastereoselective Synthesis of the Hydroperoxide-Keto Form of $( \pm)$-Steenkrotin B. Org. Lett. 2018, 20 (13), 4153-4156. https://doi.org/10.1021/acs.orglett.8b01875.

(18) Terent'ev, A. O.; Borisov, D. A.; Vil', V. A.; Dembitsky, V. M. Synthesis of Five- and Six-Membered Cyclic Organic Peroxides: Key Transformations into Peroxide Ring-Retaining Products. Beilstein J. Org. Chem. 2014, 10 (1), 34-114. https://doi.org/10.3762/bjoc.10.6.

(19) Oh, D.-C.; Scott, J. J.; Currie, C. R.; Clardy, J. Mycangimycin, a Polyene Peroxide from a Mutualist Streptomyces Sp. Org. Lett. 2009 , 11 (3), 633-636. https://doi.org/10.1021/ol802709x.

(20) Kulinkovich, O. G.; Astashko, D. A.; Tyvorskii, V. I.; Ilyina, N. A. Synthesis of $\alpha, \beta$-Epoxy Ketones from Alkyl- and Arylsubstituted Cyclopropanols. Synthesis 2001, 2001 (10), 1453-1455. https://doi.org/10.1055/s-2001-16089.

(21) Nguyen, T. L.; Ferrié, L.; Figadère, B. Synthesis of 3,5-Disubstituted-1,2-Dioxolanes: Access to Analogues of Mycangimycin and Some Rearrangement Products. Tetrahedron Lett. 2016, 57 (47), 52865289. https://doi.org/10.1016/j.tetlet.2016.10.051.

(22) Pinet, A.; Nguyen, T. L.; Bernadat, G.; Figadère, B.; Ferrié, L. Synthesis of 3,5-Disubstituted 1,2-Dioxolanes through the Use of Acetoxy Peroxyacetals. Org. Lett. 2019, 21 (12), 4729-4733. https://doi.org/10.1021/acs.orglett.9b01616.

(23) Pinet, A.; Figadère, B.; Ferrié, L. Access to Functionalized 3,5Disubstituted 1,2-Dioxolanes under Mild Conditions through Indium(III) Chloride/Trimethylsilyl Chloride or Scandium(III) Triflate Catalysis. Adv. Syn. Cat. 2020, 362 (5), 1190-1194. https://doi.org/10.1002/adsc.201901145.
(24) Dussault, P. H.; Lee, I. Q.; Lee, H.-J.; Niu, Q. J.; Schultz, J. A.; Zope, U. R. Peroxycarbenium-Mediated C-C Bond Formation: Applications to the Synthesis of Hydroperoxides and Peroxides. J. Org. Chem. 2000, 65 (25), 8407-8414. https://doi.org/10.1021/jo991714z.

(25) Beckwith, A. L. J.; Bowry, V. W. Kinetics of Reactions of Cyclopropylcarbinyl Radicals and Alkoxycarbonyl Radicals Containing Stabilizing Substituents: Implications for Their Use as Radical Clocks. J. Am. Chem. Soc. 1994, 116 (7), 2710-2716. https://doi.org/10.1021/ja00086a003.

(26) (a) Tanko, J. M. Rearrangements of Cyclobutanes. In The Chemistry of Cyclobutanes; John Wiley \& Sons, Ltd, 2006; pp 497 519. https://doi.org/10.1002/0470864028.ch11.(b) Beckwith, A. L. J.; Moad, G. The Kinetics and Mechanism of Ring Opening of Radicals Containing the Cyclobutylcarbinyl System. J. Chem. Soc., Perkin

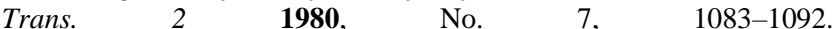
https://doi.org/10.1039/P29800001083. (c) Ingold, K. U.; Maillard, B.; Walton, J. C. The Ring-Opening Reactions of Cyclobutylmethyl and Cyclobutenylmethyl Radicals. J. Chem. Soc., Perkin Trans. 21981 , No. 6, 970-974. https://doi.org/10.1039/P29810000970.

(27) Che, C.; Qian, Z.; Wu, M.; Zhao, Y.; Zhu, G. Intermolecular Oxidative Radical Addition to Aromatic Aldehydes: Direct Access to 1,4- and 1,5-Diketones via Silver-Catalyzed Ring-Opening Acylation of Cyclopropanols and Cyclobutanols. J. Org. Chem. 2018, 83 (10), 5665-5673. https://doi.org/10.1021/acs.joc.8b00666.

(28) (a) Wang, S.; Guo, L.; Wang, H.; Duan, X.-H. Alkynylation of Tertiary Cycloalkanols via Radical $\mathrm{C}-\mathrm{C}$ Bond Cleavage: A Route to Distal Alkynylated Ketones. Org. Lett. 2015, 17 (19), 4798-4801. https://doi.org/10.1021/acs.orglett.5b02353.(b) Guo, L.-N.; Deng, Z.Q.; Wu, Y.; Hu, J. Transition-Metal Free Alkylarylation of Acrylamides Initiated by Radical C-C Bond Cleavage of the Tertiary Cycloalkanols. RSC Adv. 2016, $6 \quad$ (32), 27000-27003. https://doi.org/10.1039/C6RA03431D. (c) Wang, J.; Huang, B.; Shi, C.; Yang, C.; Xia, W. Visible-Light-Mediated Ring-Opening Strategy for the Regiospecific Allylation/Formylation of Cycloalkanols. J. Org. Chem. 2018, 83 (17), 9696-9706. https://doi.org/10.1021/acs.joc.8b01225. (d) Kurouchi, H.; Singleton, D. A. Labelling and Determination of the Energy in Reactive Intermediates in Solution Enabled by Energy-Dependent Reaction Selectivity. Nature Chem. 2018, $10 \quad$ (2), 237-241. https://doi.org/10.1038/nchem.2907.

(29) (a) Crandall, J. K.; Paulson, D. R. Small-Ring Epoxides. I. Synthesis and Reactions of a 4-Methylene-1-Oxaspiro[2.2]Pentane Derivative. J. Org. Chem. 1968, 33 (3), 991-998. https://doi.org/10.1021/jo01267a011. (b) McCullough, D. W.; Cohen, T. Preparation of 2-Vinylcyclobutanones Viam-Chloroperbenzoic Acid Oxidation of Allylidenecyclopropanes. Tetrahedron Lett. 1988, 29 (1), 27-30. https://doi.org/10.1016/0040-4039(88)80007-8.

(30) Yoshino, Y.; Hayashi, Y.; Iwahama, T.; Sakaguchi, S.; Ishii, Y. Catalytic Oxidation of Alkylbenzenes with Molecular Oxygen under Normal Pressure and Temperature by N-Hydroxyphthalimide Combined with $\mathrm{Co}(\mathrm{OAc})_{2}$. J. Org. Chem. 1997, 62 (20), 6810-6813. https://doi.org/10.1021/jo9708147.

(31) Jefford, C. W.; Jaggi, D.; Boukouvalas, J. Diastereoselectivity in the Directed Aldol Condensation of 2-Trimethylsiloxyfuran with Aldehydes. A Stereodivergent Route to Threo and Erythro $\delta$-Hydroxy- $\gamma$ Lactones. Tetrahedron Lett. 1987, 28 (35), 4037-4040. https://doi.org/10.1016/S0040-4039(01)83855-7.

(32) To determine the relative configuration of each diastereomers, we assumed that the protons at the foot of the peroxide function gives the highest coupling constant for trans-isomer, due to a higher probability to be in axial position (see Scheme 6). See also: Phillipson, D. W.; Rinehart, K. L. Antifungal Peroxide-Containing Acids from Two Caribbean Sponges. J. Am. Chem. Soc. 1983, 105 (26), 7735-7736. https://doi.org/10.1021/ja00364a045.

(33) Romero, J. A. C.; Tabacco, S. A.; Woerpel, K. A. Stereochemical Reversal of Nucleophilic Substitution Reactions Depending upon Substituent: Reactions of Heteroatom-Substituted Six-MemberedRing Oxocarbenium Ions through Pseudoaxial Conformers. J. Am. Chem. Soc. 2000, 122 (1), 168-169. https://doi.org/10.1021/ja993366o. 
(34) Woods, R. J.; Andrews, C. W.; Bowen, J. P. Molecular Mechanical Investigations of the Properties of Oxocarbenium Ions. 2. Application to Glycoside Hydrolysis. J. Am. Chem. Soc. 1992, 114 (3), 859-864. https://doi.org/10.1021/ja00029a008. 